\title{
The dialectical relationship between theory and practice in the design of an after-school mathematics club
}

\author{
Authors: \\ Debbie Stott ${ }^{1}$ \\ Mellony Graven ${ }^{1}$ \\ Affiliations: \\ ${ }^{1}$ South African Numeracy \\ Chair Project, Education \\ Department, Rhodes \\ University, South Africa \\ Correspondence to: \\ Debbie Stott \\ Email: \\ d.stott@ru.ac.za \\ Postal address: \\ PO Box 94, Grahamstown \\ 6140 , South Africa \\ Dates: \\ Received: 19 Apr. 2012 \\ Accepted: 07 Apr. 2013 \\ Published: 14 June 2013 \\ How to cite this article: \\ Stott, D., \& Graven, M. \\ (2013). The dialectical \\ relationship between theory \\ and practice in the design of \\ an after-school mathematics \\ club. Pythagoras, 34(1), \\ Art. \#174, 10 pages. http:// \\ dx.doi.org/10.4102/ \\ pythagoras.v34i1.174

\section{Copyright:} \\ (C) 2013. The Authors. \\ Licensee: AOSIS \\ OpenJournals. This work \\ is licensed under the \\ Creative Commons \\ Attribution License.
}

Read online:
In this article we describe the design process for an after-school Grade 3 mathematics club, based on our experiences running a pilot club in a 2011 research and development project. Working from a sociocultural perspective, we show the progression from an initial multifaceted design to a much simpler, more learner-centred design that speaks directly to our research foci and one which is based on empirical evidence. Our experiences have brought to light the entwined and dialectical nature of the data collection and design processes and the significance of the post-club reflection sessions as a powerful data collection instrument for planning the club sessions. Furthermore, we identify and shape the zone of proximal development for the purposes of our club as the critical design concept for each club session for each learner.

\section{Introduction}

Graven (2011) has previously argued that after-school mathematics clubs hold the potential to address some of the challenges that young numeracy learners face. We argue that numeracy clubs can be conceptualised as communities where sense making, active mathematical engagement and participation, and mathematical confidence building are foregrounded. We have elsewhere addressed the challenges of designing the clubs so as to maximise learning in relation to each of these features (Graven \& Stott, 2012). The initial design of these clubs drew largely on Valsiner's (1997) zone theory, which Goos, Dole and Makar (2007a) further developed.

This particular article focuses on how research data and our experiences piloting a Grade 3 mathematics club led to the simplification of our pre-pilot design for the clubs and for the foregrounding of the zone of proximal development (ZPD) (Vygotsky, 1978) as the central organising feature for future club activities. This dialectical praxis illuminates the relationships between theory and practice and how the dialogue between the two elements informs each.

\section{The context}

Given the many negative perceptions and poor performance of learners in numeracy in South Africa (Bloch, 2009; Fleisch, 2008; Taylor, Fleisch \& Shinder, 2008), national research funding organisations have begun to invest in research projects that focus on these specific issues. Our work within one such project is focused on both development and research in this field. In development terms we aim to improve the quality of teaching of in-service teachers at primary level and to improve learner performance in primary schools as a result of quality teaching and learning. Our research remit is to grow an area of research that looks towards finding sustainable solutions to the many numeracy education challenges faced in our area.

As part of our developmental work, we work with 15 schools in the greater Grahamstown area in South Africa. Our teacher development program involves working with 57 numeracy teachers (ranging from Grade R to Grade 6) who participate in fortnightly workshops focused on issues and challenges in numeracy teaching.

Learner activities are a key part of our developmental activities and are an area in which we are responsible for working directly with learners rather than via the teachers. As such, we facilitate learner numeracy proficiency by running learner-directed and learner-oriented mathematics activities as well as creating an ethos of 'mathematics is fun' in schools. Some examples of these activities include mathematics bonanzas and mathematics relays. However, many teachers face the challenge that most of their learners do not have the necessary mathematical foundations to be learning at the grade level in which they are placed. In light of this, we decided to implement afterschool mathematics clubs as a more focused and regular learner intervention as a possible way of addressing some of this challenge. These clubs were conceptualised by Graven (2011) as being informal places where learning can take place in out-of-school time and have been elaborated on in previous work by Graven (2011) and Graven and Stott (2012). 
The clubs are an opportunity for us to influence what happens with learners and they provide an empirical research field in which we can fully interact with the learners and thus be insiders to the learning process.

\section{Research paradigm and empirical field}

The research of our clubs and the nature of learning within it is informed by a sociocultural theory of learning and is largely interpretive and qualitative, drawing on a range of data collection methods. This article draws on our research experiences from a pilot club that we set up in the second half of 2011 for Grade 3 learners aged between 8 and 10 years in one primary school in Grahamstown. The language of learning and teaching in the school is English but many of the learners speak English as a second or third language. The school in which our pilot club ran is one of the poorer performing primary schools in Grahamstown with regard to numeracy results, as indicated by the Annual National Assessments and data collected by our larger research project. The school was participating in the professional development activities offered by our project. The club ran once a week for an hour after school for 12 sessions. The club consisted of ten learners and two mentors (the authors of this article). The participating learners invited by the Grade 3 class teacher included learners with a range of mathematical proficiencies. Participating learners were those whose parents signed consent forms and for whom after-school transport arrangements could be made. In this sense the learners were an opportunity sample. We specifically chose to work with a small group of ten learners so that both the needs of the whole group and those of the individual clubs learners could be taken into account in the design process and in the sessions themselves.

\section{Conceptualisation of the clubs}

We define our mathematics clubs as informal, afterschool clubs focused on developing a supportive learning community where learners can develop their mathematical proficiency, make sense of their mathematics and where they can engage and participate actively in mathematical activities. Individual, pair and small group interactions with mentors were the dominant practices with few interactions with the whole club.

We will briefly unpack some of these ideas here. Firstly, we explain what we mean by 'informal'. From experience with the associated teacher development project in 2011, we intentionally designed the clubs to contrast some of the more formal aspects observed in the classrooms of the participating schools. Some of these contrasts are described in Table 1.

Based on this initial conceptualisation for the clubs, our specific aim was for the clubs to promote mathematical proficiency as well as active participation. Sfard (1998) describes the differences between two metaphors for learning. 'Learning as acquisition' implies that learning is the acquisition of something which is then stored in the individual. Learning as acquisition theories can be regarded broadly as mentalist in their orientation, with the emphasis on the individual building up cognitive structures. In contrast 'learning as participation' conceives learning as a process of becoming a member of a certain community, which entails the 'ability to communicate in the language of this community and act according to its particular norms' (Sfard, 1998, p. 6). Whilst some educators argue for the need for a paradigm shift away from (or even rejecting) acquisition perspectives in favour of participation, Sfard suggests that these metaphors are not alternatives, but that each provides different insights into the nature of learning. She argues:

An adequate combination of the acquisition and participation metaphors would bring to the fore the advantages of each of them, while keeping their respective drawbacks at bay. Conversely, giving full exclusivity to one conceptual framework would be hazardous. (Sfard, 1998, p. 11)

We have purposely worked with the dialectical nature of these notions of acquisition and participation, drawing on Sfard's 'metaphorical mappings' (1998, p. 7). Working within the sociocultural paradigm, the tensions between these two approaches are seen as normal. Our design process, based on zone theory (discussed later), allowed us to plan for the types of interventions, activities, socio-mathematical norms and environment we had conceptualised. Zone theory accommodates this dialectical relationship.

TABLE 1: Contrasted classroom and club environments. 
From our experiences, different aspects of the clubs brought elements of either the participation or acquisition metaphors into focus at different times during the club sessions. This will become apparent when we discuss our data collection instruments in the following section. This dialectical approach to working with the two metaphors is by no means unique to our clubs and various studies provide some mathematical examples where this has taken place (Askew, 2004; Goos, Galbraith \& Renshaw, 2002; Jaworski \& Potari, 2009). The acquisition and participation metaphors are useful ways of accounting for evolving mathematical proficiency and participation as they occur in the social context of the club. Figure 1 shows our interpretation of Sfard's (1998) metaphorical mappings in our club context. For us the line boundary between the two is intentionally blurred as we needed to work seamlessly with dialectical nature of the two notions in our clubs.

\section{Methods of data collection}

During the pilot club, we took the opportunity to pilot the data collection instruments that we planned to use for our research.

Sfard (2001, p. 24) draws our attention to the fact that research done under the participationist metaphor umbrella will focus on the growth of mutual understanding and coordination between the learner and the rest of the community (in this case our club) and the focus will turn to the activity itself and to its changing, interactional aspects of learning. This shift of focus implies that attention will need to be given to many factors that may be deemed irrelevant when working with a purely acquisitionist metaphor.

Since we work with both notions in the club, in order to capture both the participationist and acquisitionist aspects in

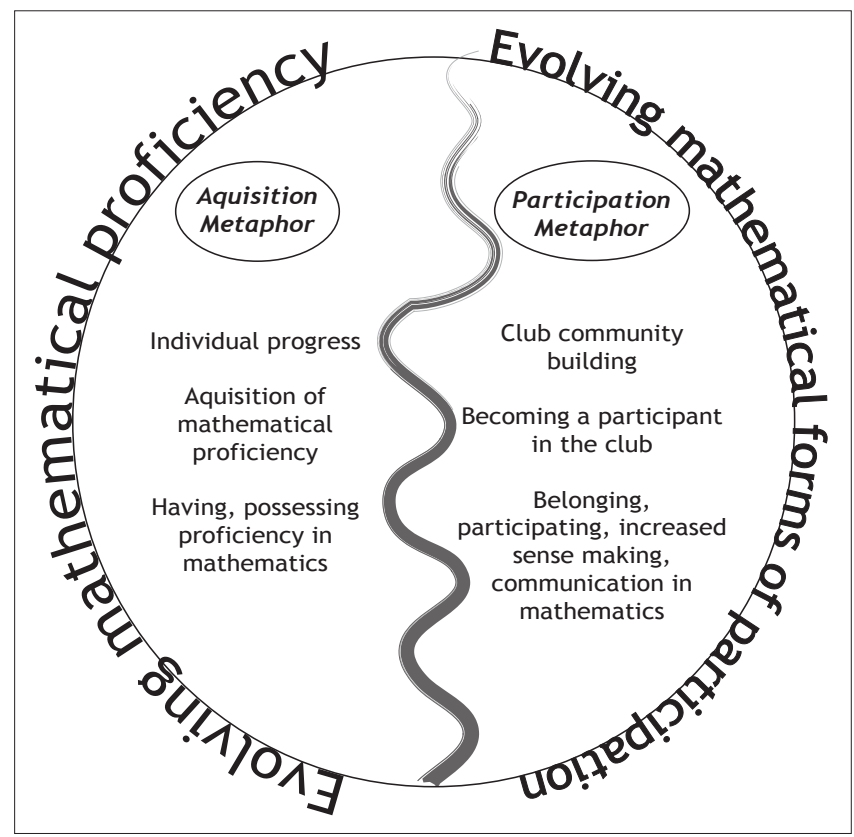

Source: Adapted from Sfard, A. (1998). On two metaphors for learning and the dangers of choosing just one. Educational Researcher, 27(2), 4-13. http://dx.doi. org/10.3102/0013189X027002004

FIGURE 1: Club metaphorical mappings. our work, we designed, planned for and used two diverse data collection instruments. The first explored learners' dispositions and participation of the club learners and the second allowed us to assess possible evolving mathematical proficiency in the club learners. For the first instrument, we designed a short interview that allowed us to gain insight into learners' mathematical dispositions and to address the fifth strand of mathematical proficiency described below (Kilpatrick, Swafford \& Findell, 2001). The two club mentors administered this instrument as a one-to-one interview with each club learner in November 2011 and learner responses were written on the interview script (see Graven [2012] for further information about the evolution of this instrument.)

The second diagnostic instrument focused on collecting data on learners' progress with regard to mathematical proficiency. Our notion of mathematical proficiency draws on Kilpatrick et al.'s (2001) definition of mathematical proficiency. This definition comprises five intertwined and interrelated strands: conceptual understanding, procedural fluency, strategic competence, adaptive reasoning and productive disposition.

This diagnostic instrument for assessing mathematical proficiency progress was derived from work done by Askew and his team during their Effective Teachers of Numeracy study (Askew, Brown, Rhodes, Johnson \& William, 1997); we were given permission to use it for our research work. We administered an adapted version of it as a whole-club oral interview at two different points in time - once in September 2011 and again in November 2011. By administering this diagnostic instrument in the first few sessions of the pilot club, we had initial data that we could compare later and that allowed us to see if learners' mathematical proficiency was evolving over time. The adapted instrument assessed:

- understanding of the number system, including place value and fractions

- methods of computation, including both known number facts and efficient and accurate methods of calculating

- solving numerical problems, including complex contextualised word problems and abstract mathematical problems concerning the relationships between operations (Askew et al., 1997, pp. 15-16).

This instrument yielded largely qualitative data and allowed us to gauge progress in all but one of the five strands of mathematical proficiency (that of productive disposition), making it an ideal instrument for use in this pilot club.

As part of the first author's doctoral study we also collected less formal data from each club session in the form of observations, journal writings, learner workings, photographs and sometimes video. These were used to record explanations given by learners in the sessions as well as to document any interactions that took place between the learners and form secondary data to support data collected from the two key instruments described above. Whilst we had not anticipated the significance of our post-club reflections, these became the key drivers for planning each 
subsequent session and re-planning and refining the data collection. These in-depth discussions took place between the mentors (the authors) every week directly following each club session and lasted on average half an hour. Detailed notes and sometimes recordings were made of what was discussed. The story of how this became critical in the design of our clubs and for our research of the clubs is elaborated in the following sections. In this way we collected both quantitative and qualitative data for the pilot club, taking a broad, concurrent mixed method approach.

\section{Ethical considerations}

Ethical permission from the university and from the Eastern Cape Department of Education was obtained through the usual procedures. Working as we were with young learners in the mathematics clubs, we obtained explicit informed parental consent in the form of signed letters, written in the appropriate home language, which explained the research and the anticipated learner involvement. In addition we received teacher, principal and district permission for each school and class that allowed the learners to participate in the mathematics clubs. As the learners were recorded via field and journal notes, video and occasional voice recordings, pseudonyms are used in subsequent publication of data. To this end, learner and where appropriate, school names have been changed. Club participation was voluntary. Learners were able to leave the club at any time if they, their teacher or parent wished them to do so. They were also free to remain in the club but withdraw from providing data for the research, in which case they are not included in any video or voice recordings.

\section{Club sessions overview}

The intention in the pilot club was to assess a number of aspects but we specifically wanted to evaluate the design process, the data collection instruments, the club size and promoted activities. Space constraints prohibit an indepth description of the club activities. The sessions were approximately an hour long and activities typically included playing mathematical games, using manipulatives such as place value cards and problem solving. The learners variously worked individually, in pairs or in groups. Further examples are illustrated below.

\section{Lessons from the pilot study Initial club design using zone theory}

Before starting the pilot club and guided by our key conceptualisations, we devised a comprehensive design for the structure and planning of the clubs. The design we chose was based on an extended version of zone theory used by Goos et al. (2007a). This design was multifaceted and gave us space to accommodate the dialectical tensions between the acquisitionist and participationist aspects of the club. On a more practical level it enabled us to conceptualise and plan how we thought the clubs might work in practice by providing us with a process for setting goals and planning and evaluating the ongoing learning programme in the mathematics clubs. As the process is iterative and cyclical we could use it to evaluate what was working and what was not and use this to plan and implement subsequent actions and activities in the clubs. Furthermore, the decision to use this model highlighted the learning environment of the clubs as a dynamic and growing entity.

Goos et al.'s (2007a) version of zone theory uses zones of promoted action to describe and plan promoted learning activities, zones of free movement to describe and plan the learning environment and the zone of proximal development to describe and consider the learner's existing understanding of mathematics. It is worth noting two other key features of their approach which they incorporated from work done by Loucks-Horsley, Love, Stiles, Mundry, and Hewson (2003). The first is the iterative nature of the design, which allows for ongoing evaluation of the planning and implementation of the environment, the activities and the possible learning that might take place. The second is that data analysis is the precursor to any planning or implementation (see Figure 3). The significance of these features will become clearer as our story unfolds.

\section{An overview of zone theory}

Valsiner (1997) expanded Vygotsky's (1978) notion of the zone of proximal development to include two additional zones of interaction: the zone of free movement (ZFM) and the zone of promoted action (ZPA). These describe the structure of a child's development in terms of the environment and relationships between the child and other people in the environment (Goos et al., 2010).

The ZFM, ZPA and ZPD can be seen as structures through which an adult or more knowledgeable other constrains or promotes a learner's thinking and acting and as such the ZFM/ZPA combination interactively generates the environment in which that learner develops. Blanton, Westbrook and Carter (2005) draw attention to a view that 'the ZFM and ZPA are dynamic, interdependent constructs that are continually being reorganized in the learning process' (p. 7). Galligan (2008) also uses the word interdependent to describe the three zones and summarises the theory skilfully: 'Valsiner's three zones constitute an interdependent system between the constraints put on the environment of the learner and the actions being promoted for the learner' (p. 2).

Whilst the ZPD may be a well-known concept to most in educational contexts and is discussed in detail later in this article, the ZFM and ZPA are less well known. For this reason we provide a brief overview of the zones as conceptualised in zone theory.

\section{The zone of proximal development in zone theory}

Valsiner (1997) regards the ZPD as a set of possibilities for development that are in the process of becoming actualised as individuals negotiate their relationship with the learning environment and the people in it. 


\section{The zone of free movement}

Hussain, Monaghan and Threlfall (2011) explain that the ZFM represents the learner-environment relationship at a particular time in a certain environmental context. They point out that it is a dynamic and social construct and is created through the social and cultural interactions of all the people in the environment. It shapes the norms and values of the environment. Galligan (2008) points out that the ZFM itself can be set up either by the adult participants, by the learners themselves or through the joint action of all participants.

In essence, the ZFM is a function of what is allowed for the learner by the adult. On the one hand, the way an adult organises the ZFM anticipates the nature of the child's thinking about the concept being taught, at that moment and in the future. In this sense, the ZFM ultimately channels the direction of development for the child, providing a framework for cognitive activity (Blanton et al., 2005; Galbraith \& Goos, 2003; Galligan, 2008; Goos et al., 2010; Goos, Dole \& Makar, 2007b).

\section{The zone of promoted action}

This is the set of activities, objects or areas in the environment through which an adult or more knowledgeable other attempts to persuade a learner to act in a certain way. The ZPA describes what the adult is promoting. However the learner is under no obligation to accept what is being promoted, as in the case where learners may not wish to actively participate (Blanton et al., 2005).

The ZPA should also be in a learner's ZPD. For example, having poor mathematics skills in a class which assumes basic mathematics skills may result in the learner's inability or reluctance to participate or learn. On the other hand those learners who believe they already have the necessary skills may not participate either (Blanton et al., 2005; Galbraith \& Goos, 2003; Galligan, 2008; Goos et al., 2010; Goos et al., 2007a).

An overview of both zone theory and the iterative nature of the process are shown in diagrammatic form in Figure 2 and Figure 3. For a more detailed discussion of this initial design, see Graven and Stott (2012). Figure 2 shows how the zones overlap to form a design for a learning community.

Figure 3 highlights the key features of the design process incorporated from Loucks-Horsley et al.'s (2003) work as highlighted in the discussion above. The three zones form the basis of the design, and the process is initially linear (analyse, set goals, plan, implement and evaluate). As a result of evaluation, the entire process starts again and, as dynamic constructs, the three zones are adjusted accordingly.

\section{Experiences from the pilot study}

During the early part of the pilot, the design of the sessions became much simpler and a more focused design emerged. Two things drove this change. The first was the data we collected using the diagnostic instrument in September and the second was the pivotal role of post-club reflection. Timely analysis of the diagnostic data collected allowed us to use a data-driven approach to determine where individual learners were struggling.

Whilst post-club reflections were an unanticipated part of our data collection, they rapidly became a fundamental part of the ongoing design, thus entwining both the data collection and design processes. Made possible by the small numbers of learners and by having two mentors, these reflections became focused on two aspects: the club activities, participation and

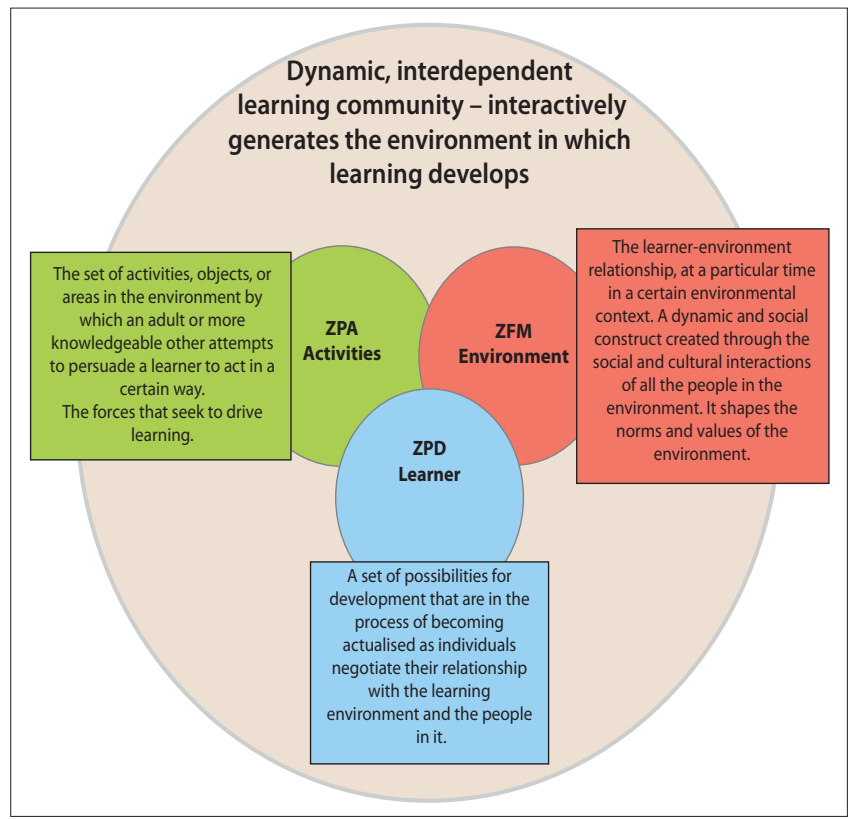

Source: Adapted from Goos, M., Dole, S., \& Makar, K. (2007a). Designing professional development to support teachers' learning in complex environments. Mathematics Teacher Education and Development, 8, 23-47

ZPA, zone of promoted action; ZFM, zone of free movement; ZPD, zone of proximal development.

FIGURE 2: Zone theory design.

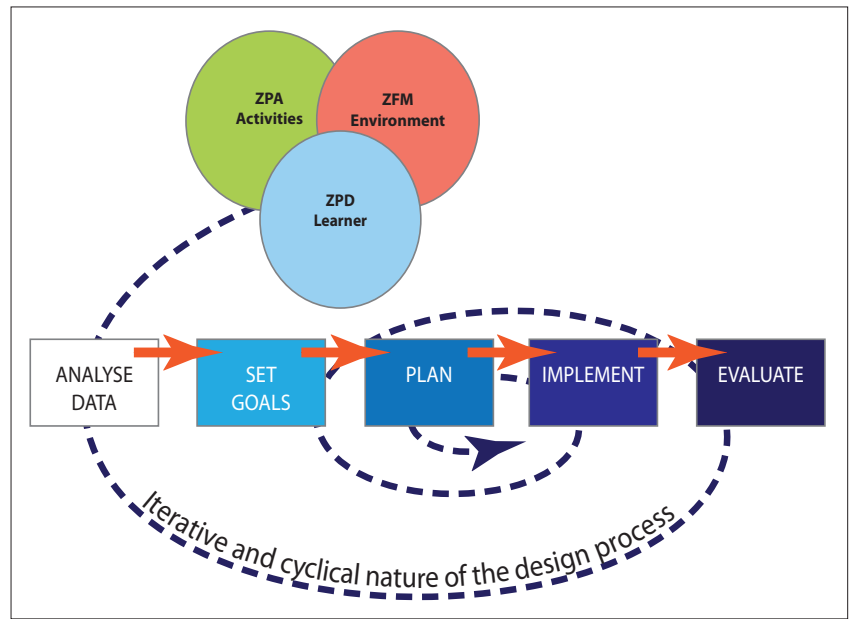

Source: Adapted from Goos, M., Dole, S., \& Makar, K. (2007a). Designing professional development to support teachers' learning in complex environments. Mathematics Teacher Education and Development, 8, 23-47

ZPA, zone of promoted action; ZFM, zone of free movement; ZPD, zone of proximal development.

FIGURE 3: Iterative nature of the design. 
progress as a whole and on individual members' participation progress and mathematical proficiency progress. These reflections and the other data enabled us to plan interventions or activities for each subsequent club session that would promote each learner's mathematical proficiency and would encourage their participation in the club.

Reflection was an integral part of our original iterative design process but it was more in the form of formal evaluation at the end of a particular implementation cycle. During the pilot we realised that our weekly, post-session reflections provided one of our key sources of rich learner data. They thus became an integral part of the data collection process from there on and provided significant input for each subsequent session design. We recognised that without these reflective events, we would not have had the insights into the learners, nor would we have arrived at a simpler, more learner-centred design that speaks directly to our research foci.

We illustrate how this reflection influenced subsequent session design with an example. In session 6, we noted that the majority of the learners were very weak on number bonds. The bonds to 5 and 10 were not recalled automatically and learners used counting on by ones or used their fingers to work them out, for example, to work out the answers to $2+8$ or $2+98$. Their grasp of basic number sense and basic bonds was severely limited so we noted that we needed to work on increasing their proficiency in these areas over a period of time. We realised that one session was not going to be sufficient to do this. After discussion, we decided to introduce some games that would allow learners to practise their bonds in an ongoing and fun way whilst also promoting interaction and communication amongst themselves and with others. In the next session we introduced a variation of a card game called Pyramid which worked with the basic bonds to 10 and which they could play individually or in pairs. In subsequent sessions we used the same game to work with bonds to 11, 12 and 13 . We gave each learner a pack of playing cards and asked them to teach the game to someone at home, so that they could practise it outside the club, with the intention of creating a third site of learning. To provide reinforcement in basic number sense and bond proficiency and to supplement the learning, we introduced the learners to a progressive series of workbooks (Brombacher \& Associates, 2012), which we found to be accessible, to involve limited reading and allowed them to work through activities at home, at their own pace and without adult supervision.

Post-session reflections had another advantage that was unexpected. Reflecting on each individual learner's participation and mathematical proficiency in each session enabled us to document and record individual learner stories in a detailed manner. Using the reflections, personal journal entries and other data, we were able to compile what we called 'individual learner story cards'. Here we recorded information about their mathematical proficiency, their disposition and attitude towards mathematics as well as their participation in the club. We could see from this how the learner was progressing (or not) in the club in terms of mathematical proficiency as well as the nature and level of their participation and engagement.

Through this process of reflecting on each individual learner's progress and proficiency, we became increasingly aware of the emergence of each learner's zone of proximal development in a way that we had not considered before. We saw distinctive and fluid ZPDs arising during sessions. We realised that by noting and discussing these we could use them to design subsequent activities, tailored for each learner. We also saw that the ZPDs arose both when we as mentors were mediating and increasingly in peer interactions, even though the learners had initially resisted this.

In this way, over the course of the pilot, the ZPD became the critical design concept for subsequent club sessions that supported individual tailoring of activities. Whilst our initial design took into account the ZPD, it was not foregrounded as a critical element; rather it was considered equally as one of the three elements (see Figure 4). Our post-club reflections allowed us to zoom into more detail about the individual learners and to focus on the ZPD aspect. This is not to say that the two other zones became irrelevant; they were simply no longer considered with the same emphasis as the ZPD and were less foregrounded. However, they were still a necessary aspect of the club design and allowed for zooming out to see and plan for the bigger picture of the club as a whole.

\section{The zone of proximal development in the clubs}

A review of the literature shows the ZPD to be conceptualised in many ways. Chaiklin (2003) points out that 'Vygotsky's concept of zone of proximal development is more precise and elaborated than its common reception or interpretation' (p. 39). We briefly discuss these different interpretations as a way of making sense of this diversity.

Primarily conceptualised as 'scaffolding' of learning by adults and teachers, the notion of the ZPD was developed by Wood, Bruner and Ross (1976). Scaffolds may take the form of more knowledgeable people or cultural resources external to the learner which support their learning. This enables them to

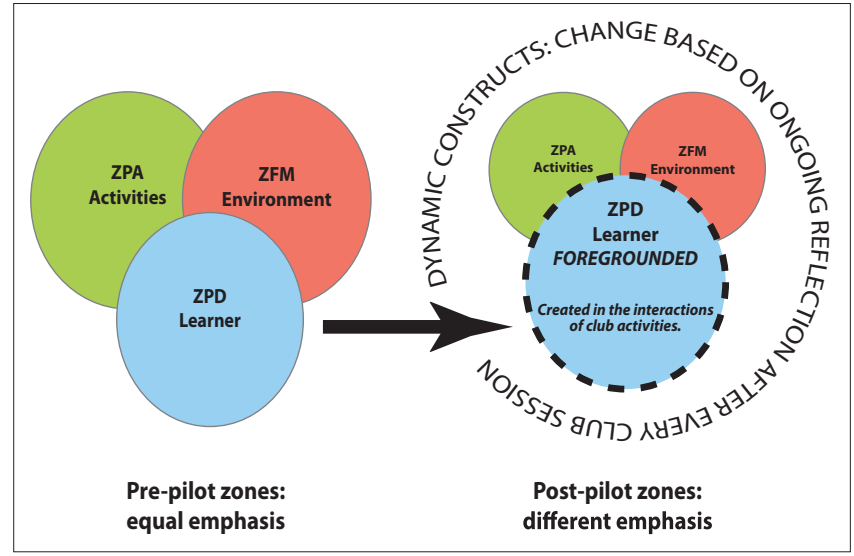

ZPA, zone of promoted action; ZFM, zone of free movement; ZPD, zone of proximal development.

FIGURE 4: Change of emphasis in the zones pre-pilot and post-pilot. 
build on their own existing knowledge and internalise new information. This interaction with a more knowledgeable other has also been called an expert-novice ZPD. This view, as Roth and Radford (2010) point out tends to result in unequal status learning:

The notion of zone of proximal development has come to be used widely to theorize learning and learning opportunities. Unfortunately, following a simplified reading of its original definition and primary sense ... the concept tends to be thought of in terms of the opposition of individuals. One of these individuals, a teacher or peer, is more capable than another individual, the learner. (p. 299, [emphasis original])

Vygotsky (1978) talked a great deal about how children learn when playing with peers. Some researchers believe that there is learning potential in peer groups and the interactions are seen as working in or creating a bi-directional or collaborative ZPD (e.g. Forman, 1989; Goos et al., 2002). In this egalitarian conceptualisation of the ZPD each partner possesses some knowledge and skill but requires the others' contribution in order to make progress.

As mentioned in the brief discussion on zone theory above, Valsiner (1997) regards the ZPD as a set of possibilities for development that are in the process of becoming actualised as individuals negotiate their relationship with the learning environment and the people in it. To explain how these possibilities actually emerge from the possible, Valsiner proposed two additional zones: the zone of free movement (ZFM) and the zone of promoted action (ZPA), which have been discussed previously. For Valsiner, these two additional zones create a better understanding of how the ZPD operates in a specific learning context.

Meira and Lerman (2001) argue that the ZPD would be better conceptualised not as a physical space, in the sense of the individual's equipment (either cognitive or communicative), but as a symbolic space involving individuals, their practices and the circumstances of their activity.

This brief view of the different conceptualisations of the ZPD affords us an overview of this complex notion and indicates that it is one that is still very current in mathematics education research. Below, we talk about the concept of the ZPD that emerged for us as most appropriate in our pilot club and thus position ourselves in this discourse.

\section{Contrasting the zone of proximal development in our initial design and what emerged from our observations}

The ZPD (as part of zone theory) was one of three equal elements of the initial design approach, which also included the ZPA and the ZFM as discussed earlier. Following Goos's (2006) example, we characterised the ZPD as 'a set of possibilities for development that are in the process of becoming actualised as individuals negotiate their relationship with the learning environment and the people in it' (p. 103). It was also important that the ZPD construct was a way of recognising the status of learners' existing understanding, which would enable us to plan activities and mediation approaches. This initial conception of the ZPD was more in line with it being interpreted as a 'physical space' that existed in the learners themselves prior to club learning activities that took place. The assumption here is that learners would bring their potential ZPD with them into the club session. This ZPD would be enabled through mediated participation in the club activities but could also be constrained and enabled by what had been acquired in previous learning episodes. This conception also assumes that the learner would then take their ZPD away from the club sessions too.

However, what we saw during the pilot was a ZPD that was much more fluid and less of a fixed set of pre-determined possibilities. It seemed to be largely determined by how the learners interacted with each activity. Additionally, what they brought to each activity was clearly dependent on a whole range of social, emotional, health and other interactional influences.

Thus, what we mean by fluid is that the ZPD was not durable from one session to another. Again, we illustrate this with a couple of examples. We noticed that one of the club learner's energy levels and health affected how she interacted and what kind of ZPD emerged for her in any given session. When her energy levels were high, she was focused, engaged, participated in the talk and made great strides in her developing proficiency. At these times an expanded ZPD emerged for her. On another occasion, by her own admission she was feeling unwell and we could see that she had reverted to her trusted finger counting strategy for working out the answers to problems posed in the activities. Understandably, she engaged with the activities in a far more limited way than she had previously and thus she didn't involve herself in any mathematical talk. A more limited and constrained ZPD emerged in the club for her that day.

Another learner, a boy called Reg, was usually quiet during sessions, did not contribute to ideas or explanations and did not seem to be fully engaged with the mathematics in a meaningful way. One could say that the ZPDs for Reg in most sessions were hampered by his stifled participation. However, one day a boy he always sat with was absent and the difference in Reg was visible: his eyes sparkled; he contributed to discussions and talked confidently to his partner during activities. For him that day, a large ZPD emerged in his interactions with us and his peers that he partnered with for various activities. Interestingly, he managed to continue this more active participation in subsequent sessions, almost as if his confidence had increased in that one session.

What we observe from these examples is that the level of mathematical participation in the club was influenced not only by the activities promoted in the club but also by energy levels (e.g. tiredness), emotional and physical factors, interactional aspects and group dynamics. These 
observations resonate with the work of Meira and Lerman $(2001,2009)$ who have used the ZPD as a tool to both analyse and design learning environments. They believe that when working from a sociocultural perspective, the ZPD may be conceptualised as a 'symbolic space involving individuals, their practices and the circumstances of their activity' and that learners can be 'pulled into their zpds by a combination of the activity, the actors, and appropriate communication' (Lerman, 2001, p. 103). This idea of pulling a learner into a ZPD by a combination of factors (activity, actors and communication) indeed surfaced from our own observations. This reasoning led us to focus on Meira and Lerman's work for exploring learning in the club.

Furthermore, Levykh's (2008) work echoed our experiences with learners: he draws attention to the affective aspects of the ZPD. Whilst aligning with Meira and Lerman's work he further highlights the ZPD as reflecting 'constant changes in the emotional connections' amongst the participants (p. 91). He states that Vygotsky was 'always a strong opponent of treating intellectual and affective aspects of human life as separate' (p. 91) and that Vygotsky combined affective and intellectual features in his notion of the ZPD.

Meira and Lerman (2001) work with a notion of the ZPD where the zones emerge or not in the activity and as a result of different ways of participating and communicating in the classroom. They also point out that the ZPD is not a generalised, context-free notion (Meira \& Lerman, 2009, p. 203). Meira and Lerman are not the only researchers to conceptualise the ZPD as a space for interaction and communication. Radford (2010) claims that the ZPD is a relational concept rather than an absolute one, one that is

forged out of the interaction between students, and between the students and their teacher. ... The ZPD is not a static thing that belongs to one particular student but rather a social, complex system in motion. (p. 116)

Roth and Radford (2010) reveal another interesting way of conceptualising the ZPD as a space for interaction and communication. They propose that asymmetries (a lack of symmetry) in the ZPD are possible because of the 'existing intercomprehension of interacting participants'. The participants can become each other's teachers and learners regardless of their actual formal or institutional positions (p. 300). If the conversation is taken as the unit of analysis, in which each word spoken has two sides or possible meanings, any asymmetry within the unit, can be thought of differently. They summarise their conceptualisation thus: 'the zone of proximal development is an interactional achievement that allows all participants to become teachers and learners' (p. 307).

Intercomprehension can be described as a dialogue between people who use two different languages and in which each one makes efforts to understand the other. In the context of mathematics, we can see this intercomprehension occurring between a teacher and learner where the teacher is talking in accepted mathematical language and the learner is using their own everyday language. Roth and Radford are saying that because the participants are effectively speaking slightly 'different' languages, their interactions can cause them to swap roles to teach and learn from each other. In this conceptualisation, the teacher is not seen as the 'more knowledgeable other' and both can enter the ZPD as equal partners.

This idea of a ZPD of equal interaction partnerships is echoed in work by Goos et al. (2002). They use the term 'collaborative $Z P D^{\prime}$ in their research on small group learning to emphasise the equal status interactions that occur in the ZPD as opposed to expert-novice notions of the ZPD, such as a more knowledgeable other.

Allal and Pelgrims Ducrey (2000) describe a learning setting where the type of interactive, formative assessment is similar to the way we use our diagnostic instrument described earlier. They point out that in this type of setting, there is a potential for multiple ZPDs to be created and for these to vary from one learner to another. The social interactions, dialogue and the appropriateness of the mediations with respect to the learners' present level of mathematical proficiency cause these zones to come into being. In this type of context, the dialogues between the different participants allows

exploration within the zone of proximal development created for a given child, at a given moment, by on-going social interaction. ... In a certain sense, the ZPD has no real existence outside the interactions that mediate the teaching-learning process. (Allal \& Pelgrims Ducrey, 2000, p. 146)

This reflects the idea that the ZPD is fragile and that it doesn't exist outside of the social interactions that take place in the learning setting. It also reinforces the idea that the combination of interactions, dialogue and mediations all affect the emergence of a ZPD in learners.

The key ideas that surface from looking at this selection of conceptualisations are that the ZPD is formed through interaction and communication during learning activities, that the participants in the ZPD have equal status and that the ZPD is a relational and complex system.

In the next section we elaborate on the ZPD as a construct as re-conceptualised based on our experiences during the course of the club pilot in 2011.

\section{Emerging zone of proximal development constructs from the pilot club}

A combination of the concepts from this pool of ideas, with a bias towards those of Meira and Lerman (2009) and Allal and Pelgrims Ducrey (2000), provides us with a set of four characteristics for our ZPD construct that have become essential for the ongoing club design.

Firstly, the ZPD does not exist prior to the activity and it is created, or not, by the social and dialogical interactions during the club activities, as part of the micro-culture of the club. These ZPDs do not 'live' in the learner and are therefore 
not necessarily carried forward to the next session of the club by the learners or into the classroom environment. In other words, they are fragile spaces. Secondly, the learner's current level of mathematical proficiency and confidence, along with their emotional and physical state, determine the type of interaction in which they can become involved and from which they can benefit. Thirdly, the participants in the learning are, in most cases, of equal status. Finally, learning may be initiated by learners as well as by mentors and is possible that there is learning for everyone involved in a specific interaction.

\section{Conclusion}

In this article we described a journey of a mathematics club design process based on our experiences with a pilot club. We highlighted the nature of the dialectic between the design process and the empirical field. We have shown how we used empirical evidence to move from an initial multifaceted design to a much simpler, more learner-centred design. Our experiences have brought to light the entwined nature of the data collection process and the design, the significance of the post-club reflection sessions as a primary form of data collection for planning the club sessions and how the combination of features described formed a ZPD construct tailored for our clubs which became the critical design concept for each session for each learner.

These findings will continue to inform the ongoing design of learner clubs in our work. The data collection process and the club sessions will be designed and planned using the same data-driven and reflective process. This article reported on our learning journey from our pilot mathematics club in 2011 to our current clubs. In 2012 we have set up nine more clubs. We plan to explore the notion of the ZPD in more depth in subsequent work.

\section{Acknowledgements}

The work of the SA Numeracy Chair Project is supported by the FirstRand Foundation (with the RMB), Anglo American Chairman's Fund, the Department of Science and Technology and the National Research Foundation. Any opinions expressed in this article are solely those of the authors.

\section{Competing interests}

The authors declare that they have no financial or personal relationship(s) that might have inappropriately influenced them when they wrote this article.

\section{Authors' contributions}

D.S. (Rhodes University) set up and was a co-mentor in the pilot club. She gathered the data, and was an integral part of the post-club reflections. She authored the manuscript and the diagrams. M.G. (Rhodes University) was a co-mentor in the pilot club and assisted with collecting data. She was an integral part of the post-club reflections. M.G. made theoretical and context contributions to the manuscript as well as suggesting how the manuscript should be structured.

\section{References}

Allal, L., \& Pelgrims Ducrey, G. (2000). Assessment of-or in-the zone of proxima development. Learning and Instruction, 10(2), 137-152. http://dx.doi org/10.1016/S0959-4752(99)00025-0

Askew, M. (2004). Mediation and interpretation: Exploring the interpersonal and the intrapersonal in primary mathematics lessons. In M. Johnsen-Høines, \& A.B. Fuglestad (Eds.), Proceedings of the 28th Conference of the International Group for the Psychology of Mathematics Education, Vol. 2 (pp. 71-78). Bergen, Norway: PME. Available from http://www.emis.de/proceedings/PME28/RR/ RR209_Askew.pdf

Askew, M., Brown, M., Rhodes, V., Johnson, D., \& William, D. (1997). Effective teachers of numeracy. London: King's College/TTA.

Blanton, M. L., Westbrook, S., \& Carter, G. (2005). Using Valsiner's zone theory to interpret teaching practices in mathematics and science classrooms. Journal of Mathematics Teacher Education, 8(1), 5-33. http://dx.doi.org/10.1007/s10857005-0456-1

Bloch, G. (2009). The toxic mix: What's wrong with South Africa's schools and how to fix it. Cape Town: Tafelberg.

Brombacher \& Associates. (2012). Number sense workbooks. Available from http:// brombacher.co.za.www11.cpt3.host-h.net/?p=730

Chaiklin, S. (2003). The zone of proximal development in Vygotsky's analysis of learning and instruction. In A. Kozulin, B. Gindis, V. Ageyev, \& S. Miller (Eds.) Vygotsky's educational theory in cultural context (pp. 39-64). Cambridge: Vygotsky's educational theor
Cambridge University Press.

Cobb, P., \& Yackel, E. (1996). Constructivist, emergent, and sociocultural perspectives in the context of developmental research. Educational Psychologist, 31(3), 175190. http://dx.doi.org/10.1207/s15326985ep3103\&4_3

Fleisch, B. (2008). Primary education in crisis: Why South African schoolchildren underachieve in reading and mathematics. Johannesburg: Juta.

Forman, E. (1989). The role of peer interaction in the social construction of mathematical knowledge. International Journal of Educational Research, 13, 5570. http://dx.doi.org/10.1016/0883-0355(89)90016-5

Galbraith, P., \& Goos, M. (2003). From description to analysis in technology aided teaching and learning: A contribution from zone theory. In L. Bragg, C. Campbell, G. Herbert, \& J. Mousley (Eds.), Proceedings of the 26th Annual Conference of the Mathematics Education Research Group of Australasia, Vol. 1 (pp. 364-371). Melbourne: MERGA. Available from http://www.merga.net.au/publications/ counter.php?pub=pub conf\&id=1377

Galligan, L. (2008). Using Valsiner. In M. Goos, R. Brown, \& K. Makar (Eds.), Navigating currents and charting directions. Proceedings of the 31st Annual Conference of the Mathematics Education Research Group of Australasia, Vol. 1 (pp. 211218). Brisbane: MERGA. Available from http://www.merga.net.au/publications/ counter.php?pub=pub_conf\&id $=544$

Goos, M. (2006). Creating learning spaces. In P. Grootenboer, R. Zevenbergen, \& M. Chinnappan (Eds.), Identities, cultures and learning spaces. Proceedings of the 29th Annual Conference of the Mathematics Education Research Group of Australasia. Canberra: MERGA. Available from http://www.merga.net.au/ of Australasia. Canberra: MERGA. Available from
publications/counter.php?pub=pub_conf\&id $=273$

Goos, M., Dole, S., \& Makar, K. (2007a). Designing professional development to support teachers' learning in complex environments. Mathematics Teacher Education and Development, 8, 23-47. Available from http://www.merga.net.au/ publications/counter.php?pub=pub_mted\&id $=58$

Goos, M., Dole, S., \& Makar, K. (2007b). Supporting an investigative approach to teaching secondary school mathematics: A professional development model. In J. Watson, \& K. Beswick (Eds.), Mathematics: Essential research, essential practice. Proceedings of the 30th Annual Conference of the Mathematics Education Research Group of Australasia, Vol. 1 (pp. 325-334). Adelaide: MERGA. http:// www.merga.net.au/publications/counter.php?pub=pub_conf\&id=399

Goos, M., Galbraith, P., \& Renshaw, P. (2002). Socially mediated metacognition Creating collaborative zones of proximal development in small group problem solving. Educational Studies in Mathematics, 49(2), 193-223. http://dx.doi. org/10.1023/A:1016209010120

Goos, M., Soury-Lavergne, S., Assude, T., Brown, J.P., Kong, C.M., Glover, D., et al. (2010). Teachers and teaching: Theoretical perspectives and issues concerning classroom implementation. In C. Hoyles, \& J.B. Lagrange (Eds.), Mathematics education and technology - rethinking the terrain (pp. 311-328). New York, NY: education and technology - rethinking the terrain (pp.
Springer. http://dx.doi.org/10.1007/978-1-4419-0146-0

Graven, M. (2011). Creating new mathematical stories: Exploring opportunities within maths clubs. In H. Venkat \& A.A. Essien (Eds.), Proceedings of 17th Annual Congress of the Association for Mathematics Education of South Africa, Vol. 1 (pp. 161-170). Johannesburg: AMESA. Available from http://www.amesa.org.za/ AMESA2011/Volume1.pdf

Graven, M. (2012). Accessing and assessing young learner's mathematica dispositions. South African Journal of Childhood Education, 2(1), 50-62. Available from http://www.uj.ac.za/EN/Faculties/edu/CentresandInstitutes/ UJICE/SouthAfricanJournalofChildhoodEducation/Documents/SAJCE2012\%20 2(1)\%20-\%20Electronic\%20copy.pdf

Graven, M., \& Stott, D. (2012). Design issues for mathematics clubs for early grade learners. In D. Nampota, \& M. Kazima (Eds.), Proceedings of the 20th Annual Meeting of the Southern African Association for Research in Mathematics, Science and Technology Education (pp. 94-105). Lilongwe: SAARMSTE. 
Hunter, R. (2008). Facilitating communities of mathematical inquiry. In M. Goos, R. Brown, \& K. Makar (Eds.), Navigating currents and charting directions. Proceedings of the 31st Annual Conference of the Mathematics Education Research Group of merga.net.au/publications/counter.php?pub=pub_conf\&id=506

Hussain, M.A., Monaghan, J., \& Threlfall, J. (2011). Extending Valsiner's zone theory to theorise student-teacher development. In C. Smith (Ed.), Proceedings of the
British Society for Research into Learning Mathematics, Vol. 31(1) (pp. 1-6). British Society for Research into Learning Mathematics, Vol. 31(1) (pp. 1-6). http://www.bsrlm.org.uk/IPs/ip31-1/BSRLM-IP-31-1-01.pdf

Jaworski, B., \& Potari, D. (2009). Bridging the macro- and micro-divide: Using an activity theory model to capture sociocultural complexity in mathematics teaching
and its development. Educational Studies in Mathematics, $72(2), 219-236 . \mathrm{http}: / /$ dx.doi.org/10.1007/s10649-009-9190-4

Kilpatrick, J., Swafford, J., \& Findell, B. (2001). Adding it up: Helping children learn mathematics. Washington, DC: National Academy Press.

Lerman, S. (2001). Cultural, discursive psychology: A sociocultural approach to studying the teaching and learning of mathematics. Educational Studies in Mathematics, 46(1-3), 87-113. http://dx.doi.org/10.1023/A:1014031004832

Levykh, M.G. (2008). The affective establishment and maintenance of Vygotsky's zone of proximal development. Educational Theory, 58(1), 83-101. http://dx.doi. org/10.1111/j.1741-5446.2007.00277.x

Loucks-Horsley, S., Love, N., Stiles, K., Mundry, S., \& Hewson, P. (2003). Designing professional development for teachers of science and mathematics. (2nd edn.). Thousand Oaks, CA: Corwin Press.

Meira, L., \& Lerman, S. (2001). The zone of proximal development as a symbolic space. Social Science Research Papers No. 13. London: Faculty of Humanities and Social Science, South Bank University. Available from http://pdf.edocr.com/56cfdca322e 369aba2f663963796b0849e4debf9.pdf
Meira, L., \& Lerman, S. (2009). Zones of proximal development as fields for communication and dialogue. In C. Lightfoot, \& M.C.D.P. Lyra (Eds.), Challenges and strategies for studying human development in cultural contexts ( $\mathrm{pp}$. 199219). Rome: Firera \& Liuzzo Publishing. Available from http://www.educazione.it/ public/Challenges\%20and\%20Strategies_2.pdf\#page $=19$

Radford, L. (2010). The anthropological turn in mathematics education and its implication on the meaning of mathematical activity and classroom practice. Acta Didactica Universitatis Comenianae - Mathematics, 10, 103-120. Available from Didactica Universitatis Comenianae - Mathematics, 10, 103-120. Av
$\mathrm{http}: / /$ www.ddm.fmph.uniba.sk/ADUC/files/Issue10/07-Radford.pdf

Roth, W.-M., \& Radford, L. (2010). Re/thinking the zone of proximal development (symmetrically). Mind, Culture, and Activity, 17(4), 299-307. http://dx.doi. org/10.1080/10749031003775038

Sfard, A. (1998). On two metaphors for learning and the dangers of choosing just one. Educational Researcher, 27(2), 4-13. http://dx.doi. org/10.3102/0013189X027002004

Sfard, A. (2001). There is more to discourse than meets the ears: Looking at thinking as communicating to learn more about mathematical learning. Educational Studies in Mathematics, 46(1), 13-57. http://dx.doi.org/10.1023/A:1014097416157

Taylor, N., Fleisch, B., \& Shinder, J. (2008). Changes in education since 1994. Available from http://www.jet.org.za/publications/research/Taylor\%20Fleisch\%20 Shindler\%20Changes\%20in\%20Education\%2015\%20year\%20review.pdf

Valsiner, J. (1997). Culture and the development of children's actions: A cultura historical theory of developmental psychology. New York, NY: John Wiley \& Sons.

Vygotsky, L.S. (1978). Mind in society: The development of higher psychological processes. Cambridge, MA: Harvard University Press.

Wood, D., Bruner, J., \& Ross, G. (1976). The role of tutoring in problem solving. Journal of Child Psychology and Psychiatry, 17, 89-100. http://dx.doi. org/10.1111/j.1469-7610.1976.tb00381.x, PMid:93212 